in importance. In this respect the biplane is best, and at present all of the R.A.F. fighter machines are of this type. Some Continental nations consider superiority in speed of greater importance, allowing the pilot to engage or break off action at will. The clean lines and somewhat smaller head resistance of the monoplane give it the advantage in this case. The biplane has another point in its favour which must be considered when making comparisons. The wing structure can be built more sturdily for a given weight, and it is consequently safer for resisting the stresses developed in high velocity diving bombing, or in very small turns at high speeds when fighting. The new Bristol monoplane is fitted with a retractable undercarriage to eliminate the resistance of that part when in the air. The motion is carried out electrically, the pilot merely having to move a switch, an indicator on the dashboard telling him the position of the wheels. This type of undercarriage has not been used on R.A.F. standard equipment up to the present.

\section{Heavy Water in Chemistry}

At the Friday evening discourse at the Royal Institution on November 23, Prof. M. Polanyi dealt with heavy water in chemistry. Heavy water has a density ten per cent greater than ordinary water. Its chemical composition is the same as that of ordinary water, two hydrogen atoms to one oxygen atom. Nor is there anything unusual about the oxygen atom. All the heaviness is due to the new kind of hydrogen discovered by Prof. H. C. Urey, which is contained in the heavy water. Its atomic weight is two instead of one. Heavy hydrogen atoms have the same structure as ordinary hydrogen atoms, only with a heavier nucleus. Such a pair of atoms would have the same chemical properties if the atoms were merely material particles. Atoms, however, are not only particles, but they are also waves: as waves, the two hydrogen atoms are different. The heavy one has a shorter wave-length. The chemical dissimilarity between the two hydrogens shows to what extent atoms behave as waves and not as particles.

THE chemical differences of ordinary and heavy water make it possible to extract heavy water from its natural dilution of one part in four thousand and prepare it in pure form. The preparation is still a very expensive operation, but methods can be outlined by which it might be considerably cheapened. Heavy hydrogen might then be used in the manufacturing of drugs and dyestuffs, if its properties should turn out to be useful, for example, if it shows greater stability than the products made of ordinary hydrogen. With heavy hydrogen, reactions can be discovered in which chemically nothing is changed, because all that happens is an interchange of hydrogen atoms. When part of the hydrogen atoms are 'labelled' by being of heavier sort, this interchange becomes apparent. Some well-known chemical reactions of hydrogen appear now as subordinate effects of this hitherto undiscovered interchange process. When, for example, hydrogen is added to benzene forming hydrobenzene, for every molecule adding on hydrogen there are a hundred molecules which react with hydrogen in the way of an interchange. It seems that hydrogenation may be just an occasional by-reaction of this main interchange process. Following this line, the atomic mechanism of hydrogenation can be worked out completely.

\section{Preservation of Scenic Amenities}

THE necessity for preserving the scenic amenities of the countryside is fortunately gaining more attention, and there is hope that some of the worst vandalism may be checked before it is too late. But the dangers of urban growth are still insistent, and to this topic Dr. Vaughan Cornish refers in an article in Geography of September on the scenic amenity of Great Britain. It is not only the growth of radial suburbs with their monotonous plans, but also the reconstruction of existing urban centres that needs to be controlled. The nineteenth century saw the spoliation of many picturesque market towns and beautiful cathedral cities and the growth of urban 'deserts' on the coalfields. Among the few examples of urban scenery from which Nature has not been expelled are the west end of London, the collegiate parts of Oxford and Cambridge and the precincts of most cathedrals. It is to be hoped that in schemes of reconstruction the dignified architecture of the eighteenth century, where it exists, will be preserved, while in the replacement of the closely packed streets of the Victorian era due regard should be paid to the possibility, with modern constructional materials, of accommodating the people on half the area by doubling the height of the houses and so leaving space for town gardening and afforestation. The conversion of every city into a garden city is the most important consideration in the replanning of towns, and this must entail the abandonment of formal lines which are so tiring to the eye.

\section{Recent Acquisitions at the Natural History Museum}

Among the recent acquisitions at the British Museum (Natural History), the Department of Zoology has received as a donation from the Rowland Ward Trustees an exceptionally fine mounted head of the Tian-Shan wapiti, and from Sir Arnold Hodson, Governor of the Gold Coast, a further skull of the so-called dwarf elephant, or 'Sumbi', from the Gola Forest, Sierra Leone. This specimen is a young individual of the forest elephant. The horns of a white rhinoceros from the Belgian Congo have been presented by Mr. Stanley C. Tomkins. This gift is of special interest in that the Museum already possesses the skull to which these horns belong. One hundred and fifty birds of 76 different kinds collected in the dry thorn bush region of the West Usambara Mountains, Tanganyika Territory, have been purchased, and also an interesting collection of more than 200 birds from Serbia and Macedonia. Extensive collections of insects made during the summer months of 1931, 1932 and 1933 by members of the staff of the Department of Entomology in the Scottish Highlands are beginning at last to yield interesting results. More than 7,000 specimens were obtained and added to the collections, and among them so 
far more than 50 species have been recognised that have not previously been recorded from Great Britain, including at least 13 new to science. The particular aim of the collecting undertaken was the study of the fauna occurring in association with the relict arctic-alpine flora peculiar to elevations above $2,500 \mathrm{ft}$. In one group alone, consisting of the sawflies, four species new to science, and 13 new to Great Britain were obtained, with a total of 18 species peculiar to the region specially investigated.

\section{Botany at the Natural History Museum}

Mr. J. D. SNowden has presented to the Department of Botany his herbarium of 2,300 plants. During his period of service as agricultural officer in Uganda, Mr. Snowden was an enthusiastic botanical collector with great opportunities of which he made full use. His collections rank, both in number and quality, among the best from the Protectorate, and include many plants discovered by himself. The specimens presented to the Museum formed his own personal set. Some of the plants were collected in the littleknown Acholi Hills in the south of the Sudan, but the great majority came from Uganda, particularly from Mount Elgon, the flora of which-like that of the other great African mountains-is of exceptional interest. As an agricultural officer, Mr. Snowden knew just what was required, and his material is accompanied by adequate notes. He paid special attention to grasses, a group in which his name is commemorated by the genus Snowdenia.

SIR J. L. Hanham, who accompanied Mr. J. M. Wordie's recent arctic expedition, made a collection of plants from West Greenland (500 numbers) and Baffin Land (200 numbers), together with a few lichens and mosses. Plants in the arctic are well known to be shy flowerers, and this collection contains exceptionally good specimens; they are unusually well dried, whereas so many arctic collections have suffered much from mould and mildew owing to the great humidity of the atmosphere in high latitudes. As a result, this collection is a valuable one apart from the fact that it has been made in little-known regions. Mrs. E. M. Day has presented the paintings of larger fungi made by her late husband. They number 1,400. Most of them have been examined by eminent mycologists or have been drawn from specimens named by them. An interesting fern herbarium of about 500 specimens from Trinidad has been presented by Archdeacon A. Hombersly. The herbarium is in very good condition and is of particular value as the donor used his collection as the basis of an account of the ferns of Trinidad which is now being prepared for Press. Mr. E. Heron-Allen has presented a copy of the valuable first edition of the "Thesaurus Evonymi Philiatri de remediis secretis", by Conrad Gesner, 1557. This is a rare book, particularly in the first edition. It makes an interesting addition to the collection of herbals in the Department of Botany.

\section{Die Physik}

THE quarterly journal Die Physik in Regelmässigen Berichten, which is sponsored by the German Society for Technical Physics, has completed its second year. As the full title implies, its contents are mainly surveys of larger or smaller fields of physics, the average length of an article being about 15 pages. The thirteen subjects dealt with range widely, and include hygrometry, acoustics, medical physics, corpuscular radiations and general quantum theory, the balance between the old and the new physics being carefully maintained. It is presumably the intention to give further surveys with the same titles, as the subjects develop, since the title of each article is followed by the numeral I. The reviews appear very thorough, considering the space available, and are all by acknowledged experts in their subjects. Thus F. Henning writes on thermal apparatus, M. Pirani on illuminants and illumination, W. O. Schumann on dielectrics and $\mathrm{G}$. Wentzel on quantum theory and wave mechanics.

A FEATURE of the publication is the method of citing references to investigations mentioned in the surveys. Whenever possible, the volume and page number of the abstract in the Physikalischen Berichte is given, without more detailed reference, a note at the end of every article explaining that this has been done. Additional references are collected together at the end of the survey. An innovation which seems to have little to recommend it is that of numbering the pages of each survey independently, and printing this page number on the top corner of the leaf. A second set of page numbers running serially through the volume is also provided, but is in a less conspicuous position, at the bottom corner of the leaf. The periodical is published by J. A. Barth of Leipzig, and the annual subscription (post free) is 24.60 gold marks.

\section{A New Modified Bunsen Burner}

THE Bunsen burner is one of those simple and ingenious contrivances that could only have emanated from the brain of a practical genius. Unlike some of his successors to-day, Bunsen was never a SchreibtischChemiker; flouting speculative hypotheses, he excelled in practical work of many kinds, and in devising his celebrated burner he created for himself a memorial that may well outlast his fame as an analytical investigator. Generations of chemists and physicists come, use his burner, and go; yet the principle of it stands fast. From time to time a useful modification, for example, the Meker and the Teclu, arises, and the latest, which has recently been marketed by Messrs. Amal Ltd., of Birmingham, appears to belong to this category. In this burner, a very sensitive control of the gas flow is obtained by means of a needle-valve, inserted in the orifice of the jet, which is capable of very fine adjustment by an external screw. Air-regulation is unnecessary, and the flame can be reduced almost to invisibility, by means of the needle-valve, without flashing back. As in the Meker burner, the combustion-head is perforated with many small holes, so that the flame consists of a cluster of perfectly aerated small cones. Attached to the base is an insulated hooked strip of metal for use as a holder should the burner become 